\title{
Rather-high-frequency sound scattering by swimbladdered fish
}

\author{
Kenneth G. Foote \\ Institute of Marine Research, 5011 Bergen, Norway
}

(Received 18 December 1984; accepted for publication 15 April 1985)

\begin{abstract}
A new model describes acoustic scattering by swimbladdered fish of lengths from at least 8 to 36 wavelengths. It represents a fish by an ideal pressure-release surface having the exact size and shape as the swimbladder. The backscattering cross section, or target strength, is computed by means of the Kirchhoff approximation. To test the model, predictions of target strengths based on swimbladder morphometries of 15 gadoids of lengths from 31.5 to $44.5 \mathrm{~cm}$ are compared with conventional target strength measurements on the same, surface-adapted fish, anesthetized before acoustic measurement, and shock-frozen immediately afterwards. Details are given of the swimbladder morphometry. In essence, this consists of slicing the frozen fish with a microtome, photographing the exposed swimbladder cross sections, digitizing the contours, and triangulating the surface between pairs of contours on adjacent, parallel planes. Theory and experiment are compared through the dorsal and ventral aspect target strength functions, their averages, and simulated probability density functions.
\end{abstract}

PACS numbers: 43.20.Fn, 43.30.Dr, 43.80.Jz

\section{INTRODUCTION}

The backscattering cross section, or target strength, of fish is a pivotal quantity in the acoustic assessment of fish abundance. ${ }^{1}$ As a result, it has been the object of numerous and diverse studies. These have included in situ measurements, controlled measurements on tethered or encaged fish, and modeling. Without repeating Midttun's comprehensive review, ${ }^{1}$ the measurement side of target strength determination has had its successes, but generally suffers from the particularity of the measurement situation when the fish target is known, and unknown behavioral effects when the fish target is constrained.

The alternative to fish measurement is modeling. There apparently has been substantial interest in this, divided between measurements on artificial models ${ }^{2-11}$ and theoretical computations. ${ }^{12-24}$ The number of distinct models has been small, however, undoubtedly owing to the dominance, if not preeminence, of the swimbladder in scattering by fish. ${ }^{11,25-27}$ While the individual models serve their authors' original purposes, they are unsatisfactory for $a$ priori determinations of the target strength of commercially important fish at the usual ultrasonic survey frequencies, above about $30 \mathrm{kHz}$.

Specifically, models based on simple geometric shapes, e.g., sphere, prolate ellipsoid, and finite circular cylinder, are inadequate, if only because such shapes are symmetrical with respect to the horizontal or transverse plane, while the general swimbladder is not. ${ }^{28-38}$ The consequence of asymmetry in swimbladder form is often observed in the significant asymmetry of dorsal and ventral aspect target strength functions of the same fish. ${ }^{39,40}$ Admittedly, many uses of simple shapes have been directed to resonant or other lowfrequency scattering where the target strength is independent of fish orientation. A rare success of a simple-shape model at high frequencies is Kalikhman's computation of backscattering by a $27-\mathrm{cm}$ herring (Clupea harengus) at 30 $\mathrm{kHz}^{18,22}$
Models based on arrays of point scatterers, as in Refs. 21 and 24, while apparently successful in simulations of echo statistics, including the representation of behavioral effects, are relative. As such, they depend on a posteriori knowledge of target strength as a function of orientation for determination of the point-scattering strengths. Thus they cannot, in themselves, predict absolute magnitudes of target strength. For this, recourse to actual measurement is necessary.

Composite and whole-fish-body models have also been proposed to describe scattering by swimbladdered fish. These, together with measurements on artificial models, are disregarded for being unnecessarily complicated.

It is the present aim to introduce a simple model for scattering by swimbladdered fish which, at the least, is applicable for rather high frequencies, with fish lengths in the nominal range from 8 to 36 acoustic wavelengths. The new model resembles the basic bubble-type model in representing fish entirely by the swimbladder, which is equated to an ideal pressure-release surface. Unlike its predecessors, however, the swimbladder form is not approximated by a simple shape; rather, it is assumed to have the very size and shape of the organ, as morphometrically determined and mathematically represented by a finite-element triangulation. In keeping with the intent of the model, the scattering amplitude is computed by means of the Kirchhoff approximation, hence without the effects of diffraction.

To demonstrate the power of the model, predictions are made of the dorsal and ventral aspect target strength functions of 15 fish, at each of four frequencies, from the respective swimbladder morphometries. These are compared with conventional measurements performed on the same fish, anesthetized and tethered, before shock-freezing and eventual anatomical measurement. The principal criteria used to compare theory and experiment are based on the two expressions of target strength most widely used in fisheries acoustics: the average and the probability density function. In addition to considering the computational results, limitations 
of the model and challenges for it are discussed. The findings or achievements of the model are summarized in the Conclusions.

\section{MODEL}

A swimbladdered fish is represented entirely by its swimbladder. This is assumed to be ideally pressure-releasing. Sound scattering is thus described by the solution of the scalar wave equation exterior to a soft shape, or closed surface with a homogeneous Dirichlet boundary condition.

Solution is achieved by the Kirchhoff approximation. ${ }^{41}$ Accordingly, the pressure field on the scattering surface is equated to that which would obtain on the front side of the same surface if there were no diffraction. The solution for the monochromatic backscattering amplitude $F$ due to planewave ensonification of the surface $S$ is

$$
F=\lambda^{-1} \oint_{S} \exp (2 i \mathbf{k} \cdot \mathbf{r}) \mathscr{H}(\hat{k} \cdot \hat{r}) \cos (\hat{k} \cdot \hat{r}) d S,
$$

where $\lambda$ is the acoustic wavelength, $\mathbf{k}$ is the wave vector in the source or backscattering direction, $\hat{k}=\mathbf{k} / k, \mathrm{r}$ is the position vector of the surface element with infinitesimal area $d S$, and $\mathscr{H}(x)$ is the Heaviside step function with values 1 for $x>0, \frac{1}{2}$ for $x=0$, and 0 for $x<0$. Related expressions are found in Ref. 42 for a surface of arbitrary reflectivity, and in Refs. 43-45 for rigid surfaces.

For the present application to fish scattering, the observable quantity corresponding to $F$ is the backscattering cross section. Given the customary use of finite-signal waveforms and finite-bandwidth receivers, the operational definition of backscattering cross section $\sigma$ is appropriate; name$1 y,{ }^{46}$

$$
\sigma=4 \pi \int_{0}^{\infty}|S F H|^{2} d \omega / \int_{0}^{\infty}|S H|^{2} d \omega,
$$

where $S$ is the signal spectrum, $H$ is the receiver frequency response function, and $\omega$ is the angular frequency, $\omega=c k$, where $c$ is the medium sound speed.

In the case of narrow-band $S$ and $H$, or long, simple signals and narrow-band receivers, Eq. (2) can be significantly reduced. The result is the usual monochromatic backscattering cross section

$$
\sigma=4 \pi|F|^{2} \text {. }
$$

For convenience, the backscattering cross section is also expressed through its logarithmic measure, the target strength. This is defined in the traditional manner, ${ }^{47}$ although with use of SI units,

$$
T S=10 \log \sigma / 4 \pi .
$$

The target strength of the idealized perfectly reflecting sphere of $2-\mathrm{m}$ radius is thus $0 \mathrm{~dB}$.

\section{MATERIALS AND METHODS}

The source of data on the swimbladder form was identical to that of the comparative acoustic measurements. This was 13 pollack (Pollachius pollachius) and two saithe (Pollachius virens), part of a special sample of 20 fish that were, in turn, measured acoustically and then shock-frozen on 24 July 1980, during a one-day digression from the larger exper- iment described in Ref. 48.

The acoustic measurements were performed in the invariable manner of the larger experiment, resembling earlier measurements too. ${ }^{39,49-51}$ Individual, surface-adapted fish were anesthetized, tethered in a suspension system, and measured, under tilting, at each of four frequencies, in both dorsal and ventral aspects. Earlier suspicions that similar pollack were not adapted to the shallow surface layer ${ }^{48}$ are no longer held by this author, who accepts Ona's attribution of the extreme orientations of the encaged swimming fish to the smallness of the cage in lateral extent. ${ }^{52,53}$

The acoustic frequencies and pulse durations of the echo sounder signal were measured a number of times during the larger experiment. The result of interpolating these for the mentioned date is shown in Table $I$.

Following the acoustic measurements, the basic biological characteristics of length and weight were measured. The still-anesthetized fish were then grasped by tongs at snout and tail, held tautly in normal, extended, horizontal posture, and totally immersed in a bath of alcohol maintained at a temperature of $-50^{\circ} \mathrm{C}$ by the addition of dry ice. It was held in the same posture for the several minutes required for thorough freezing. The fish were then tagged and stored in an insulated box containing dry ice. Upon completing the particular measurement series, the 20 fish were transferred to a large freezer at the author's institute for long-term storage at $-35^{\circ} \mathrm{C}$.

In February 1981, the fish were removed from the freezer for anatomical measurement. Prior to slicing with a microtome, with nominal $1-\mu \mathrm{m}$ accuracy, the fish were encased in rectangular blocks of carboxymethyl cellulose (CMC). This was accomplished by immersing the frozen fish in a solution of CMC and water held in the microtome's freezing frame, followed immediately by freezing of the entire system by immersion in a bath of alcohol and dry ice maintained at a temperature of $-70^{\circ} \mathrm{C}$.

The fish-encasing block was trimmed in even thicknesses of $200 \mu \mathrm{m}$ until the fish was exposed. It was then sliced in even thicknesses of $100 \mu \mathrm{m}$, enabling rapid changes in swimbladder form to be detected. The slicing was performed in the sagittal plane to minimize the amount of photography. The swimbladder cross sections were photographed at intervals varying from 200 to $1400 \mu \mathrm{m}$ in order to allow significant detail to be registered for the eventual reconstruction of the three-dimensional surface.

In the course of the slicing, four of the 20 specimens were irremediably damaged. A fifth specimen was lost to further work by loss of the alignment reference under pho-

\begin{tabular}{|c|c|c|c|c|}
\hline \multirow{2}{*}{$\begin{array}{l}\text { Echo } \\
\text { sounder }\end{array}$} & \multicolumn{2}{|c|}{ Center frequency $(\mathbf{k H z})$} & \multicolumn{2}{|c|}{ Pulse duration (ms) } \\
\hline & Nominal & Measured & Nominal & Measured \\
\hline EK-38 & 38.0 & 38.1 & 0.6 & 0.64 \\
\hline EK-50 & 49.5 & 49.6 & 0.6 & 0.57 \\
\hline EY-M & 70.0 & 68.4 & 0.6 & 0.60 \\
\hline EK-120 & 120.0 & 120.4 & 0.6 & 0.68 \\
\hline
\end{tabular}
tography.

TABLE I. Center frequencies and durations of pulses transmitted by four Simrad echo sounders. 
Table II. Biology of the 15 fish specimens of the investigation. The swimbladder data are derived from the triangulations.

\begin{tabular}{|c|c|c|c|c|c|}
\hline \multirow[b]{2}{*}{$\begin{array}{l}\text { Fish } \\
\text { no. }\end{array}$} & \multirow[b]{2}{*}{ Species } & \multirow[b]{2}{*}{$\begin{array}{l}\text { Length } \\
(\mathrm{cm})\end{array}$} & \multirow[b]{2}{*}{$\begin{array}{c}\text { Mass } \\
\text { (g) }\end{array}$} & \multicolumn{2}{|c|}{ Swimbladder } \\
\hline & & & & $\begin{array}{c}\text { Surface } \\
\text { area }\left(\mathrm{cm}^{2}\right)\end{array}$ & $\begin{array}{l}\text { Volume } \\
\left(\mathrm{cm}^{3}\right)\end{array}$ \\
\hline 201 & Pollack & 31.5 & 195 & 39.03 & 6.88 \\
\hline 202 & Pollack & 44.0 & 533 & 69.47 & 16.37 \\
\hline 204 & Pollack & 35.5 & 321 & 52.57 & 10.16 \\
\hline 205 & Pollack & 39.0 & 380 & 56.54 & 11.31 \\
\hline 206 & Pollack & 35.0 & 287 & 35.46 & 7.83 \\
\hline 207 & Pollack & 44.5 & 635 & 89.35 & 19.76 \\
\hline 209 & Saithe & 38.5 & 385 & 48.37 & 10.12 \\
\hline 213 & Pollack & 34.5 & 259 & 45.06 & 7.18 \\
\hline 214 & Pollack & 39.0 & 406 & 54.21 & 9.82 \\
\hline 215 & Pollack & 37.0 & 332 & 40.89 & 8.27 \\
\hline 216 & Pollack & 36.5 & 343 & 48.79 & 10.46 \\
\hline 217 & Pollack & 34.5 & 253 & 39.30 & 6.61 \\
\hline 218 & Pollack & 32.5 & 257 & 35.26 & 6.28 \\
\hline 219 & Pollack & 35.5 & 292 & 40.10 & 8.04 \\
\hline 220 & Saithe & 38.0 & 406 & 53.87 & 10.57 \\
\hline
\end{tabular}

The basic characteristics of the surviving 15 fish specimens, the subjects of the present investigation, are shown in Table II. The fish numbers refer to the order of acoustic measurement in the more extensive target strength measurement series performed during the experiment described in Ref. 48.

All of the biological measurements were performed by Egil Ona, who devised the shock-freezing technique, in addition to another technique, for morphometric studies of the swimbladder. ${ }^{52}$

\section{SWIMBLADDER-SURFACE TRIANGULATION}

Representation of the swimbladder surface for evaluation of Eq. (1), hence for realization of the model, is achieved through a triangulation. This is performed independently for each pair of adjacent contours. When combined with triangulations of the end surfaces, the surface mapping is complete.

\section{A. Manual procedures}

The triangulation commences with a digitization of each sagittal cross section. This is conveniently effected by tracing the outline, or contour, of the inner swimbladder wall boundary on photographic print with a cursor connected to a digital computer. Prior enhancement or marking of the contour by a knowledgeable fisheries biologist is useful, if not necessary, to avoid problems of interpretation. Because of the general complexity in form of gadoid swimbladders, often characterized by a lobed structure due to lateral protrusions of the swimbladder between ribs, the apparent contour may not be convex. In fact, it may not be star-shaped, and may even be disconnected. Several contour types are illustrated in Fig. 1.

The next task in the triangulation procedure is pairing of connected contours on adjacent, parallel planes. This may entail cutting connected contours for matching with disconnected contours on the next plane, especially if lying outwards from the medial plane of the fish. It may also involve
CONVEX

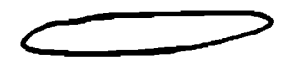

NON CONVEX STAR-SHAPED

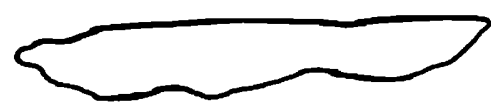

SIMPLY - REENTRANT

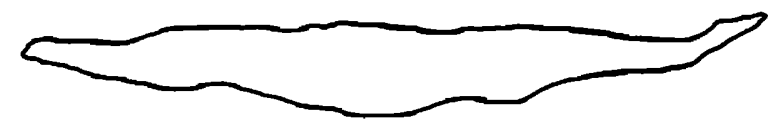

MULTIPLY-REENTRANT

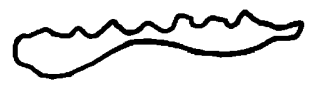

DISCONNECTED

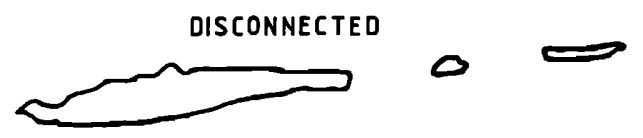

FIG. 1. Illustration of contour types, derived from actual swimbladder sagittal cross sections.

cutting of severely pinched connected contours to avoid unnatural treatment as reentrants by the automatic algorithm which effects the triangulation.

Preparation of the digitized contours for triangulation is completed by ensuring that the points are arranged with the same rotation sense, or handedness. For definiteness, this is chosen to be counterclockwise.

\section{B. Automatic algorithm}

The surface between pairs of connected contours on adjacent, parallel planes is now triangulated by means of the following algorithm. The numbers of points on the two digitized contours are compared. That contour with the smaller number is called the "lesser." The points of each contour are referred to the planar centroid of the lesser contour, and then mapped onto the respective unit circle. This occurs by radial projection where possible. Reentrants present the single exception; their points are mapped consecutively and evenly onto the arc between those radially projected, bounding points that preserve the counterclockwise order. The degenerate case of reentry, in which successive points have the same radial projection, is treated as an ordinary case of reentry. The mapping of points of a simple connected contour onto the unit circle is thus homeomorphic.

The unit circle corresponding to the "greater" contour, the "outer" circle, provides the frame of reference for the next operation. In this, points are sought on the "inner" circle with angular locations intermediate to those of each pair of successive points on the outer circle. Wherever there is not at least one intermediate point on the inner circle, one is created by interpolation.

Triangulation of the cylindrical surface between the two unit circles, which are aligned and on parallel planes by de- 

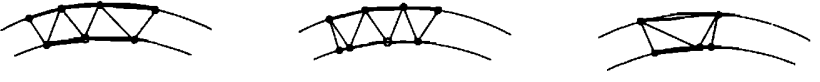

FIG. 2. Illustration of triangulation by angular affinity. Solid circles represent points obtained by the standard homeomorphic mapping. Open circles represent interpolated points.

finition, is now accomplished. Points on alternate circles are joined on the basis of angular affinity, as illustrated in Fig. 2 .

The original coordinates of the projected points, now become the vertices of triangles, are restored. The coordinates of interpolated points are established as the medians of their immediate neighbors on the same, lesser contour.

The special case of end surfaces is treated in the following manner. All contours lacking appropriate mates on adjacent planes are identified. Single, isolated points, called "endpoints," are added to planes midway between the contour-containing plane and nearest slice. Multiply reentrant or severely pinched, singly reentrant contours are cut to form a set of more simply connected contours. The planar position of each endpoint is defined by the planar centroid of the contour needing pairing. The surface between endpoint and contour is triangulated by a simple connection of contour points to the endpoint, which serves as the common vertex of a system of triangles whose bases are the segments between successive points along the contour.

The algorithm concludes with determination of the median position vector, outward normal unit vector, and area of each triangle.

\section{Checking routines}

Given the complexity of most contours and the desire to effect the triangulations by an automatic algorithm, it is convenient to employ checking routines during the data analysis. Examples are enumerated.

(1) Plotting of the cross sections exactly as digitized. Hard-copy plots may be compared directly with the raw material in the form of photographic prints.

(2) Computation of distances between adjacent points on each contour. Summary of the distances in a histogram for all contours of the same swimbladder enables the fineness of digitization to be confirmed. At the same time, the uniqueness of each digitized point can be established, thereby avoiding having to do the same in the automatic algorithm.

(3) Superimposed plotting of matched pairs of contours. This routine permits a final confirmation of the basic material, particularly after its undoubted transformation by alignment and scaling operations following the initial digitization and plotting.

(4) Statistical analysis of triangle areas. Summary of the areas of the finite-element triangles in a histogram is convenient, although not foolproof, for confirming the working of the algorithm. Extreme, unusual, or new geometries may very well produce individual elements with large areas. The same routine may confirm the absence of element areas with negative values. These may arise in the automatic algorithm with very small values, consistent with underflow, or lack of precision in the floating-point operations. At the time of their detection, such negative values should be recorded, for later inspection, and replaced by nulls.

(5) Computation of the total swimbladder surface area and volume. These quantities are useful for comparison with gross estimates of the same when derived from the maximal swimbladder dimensions and assumption of prolate ellipsoidal form.

\section{Data statistics}

The digitization was performed with equipment with a nominal positioning accuracy of $10 \mu \mathrm{m}$. This was reckoned to exceed the realized precision by a factor of 10 to 20 . Lengths in the resulting triangulation were therefore expressed to the nearest $0.01 \mathrm{~cm}$.

The listed checking routines were exercised for each swimbladder triangulation. The result of combining all 15 histograms of digitization-segment lengths was a slightly skewed, nearly normal distribution with a mean of $1.25 \mathrm{~mm}$ and a standard deviation of $0.38 \mathrm{~mm}$. Analysis of the element areas revealed an approximately exponential distribution with mean of $0.72 \mathrm{~mm}^{2}$.

Gross swimbladder dimensions are presented in Table III. In estimating the swimbladder surface area and volume, the height and width of the swimbladder were averaged, and the overall form assumed to be that of a prolate ellipsoid. Companison with the ralues derived from the tringulations, also shown in Table II, indicates the expected greater complexity of the actual form.

\section{RESULTS}

The fundamental computational quantity is the backscattering cross section, or target strength, as a function of the ensonification conditions and fish orientation. This has been determined systematically for each of the 15 fish specimens whose swimbladder surfaces were triangulated. Computations were performed in accordance with the simple finite-element, or numerical, realization of Eq. (1). The difference in wideband and monochromatic target strengths was found to be negligible for the several fish examined comparatively in this way; hence the simpler monochromatic formula, Eq. (3), was uniformly used in the basic theoretical computations.

An example of the basic computations performed for each fish is shown in Fig. 3 for fish No. 201, a 31.5-cm pollack. The tilt angle is defined as the angle made by the centerline, or imaginary line running from the root of the tail to the tip of the upper jaw, with the horizontal plane. The sign convention is that positive angles denote head-up orientations; negative angles, head-down orientations. Presented with the theoretical target strength functions are the actual measured functions. The respective correlation coefficients are shown. These are based on the backscattering cross section.

The result of combining the corresponding target strength functions of each of the 15 fish is shown in Fig. 4. As with the correlation coefficients, the domain of combination is the backscattering cross section. The arithmetic average of the backscattering cross section is formed, therefore, before 
TABLE III. Gross dimensions, surface area, and volume of the swimbladder when represented as a prolate ellipsoid. Corresponding triangulation-derived measures are presented together with the relative error.

\begin{tabular}{|c|c|c|c|c|c|c|c|c|c|c|}
\hline \multirow{2}{*}{$\begin{array}{l}\text { Fish } \\
\text { no. }\end{array}$} & \multirow{2}{*}{$\begin{array}{c}\text { Fish } \\
\text { length } \\
\text { (cm) }\end{array}$} & \multicolumn{3}{|c|}{$\begin{array}{c}\text { Maximal swimbladder } \\
\text { dimensions }(\mathrm{cm})\end{array}$} & \multicolumn{3}{|c|}{$\begin{array}{c}\text { Swimbladder surface } \\
\text { area }\left(\mathrm{cm}^{2}\right)\end{array}$} & \multicolumn{3}{|c|}{$\begin{array}{c}\text { Swimbladder volume } \\
\left(\mathrm{cm}^{\mathbf{3}}\right)\end{array}$} \\
\hline & & Length & Height & Width & Ellip. & Triang. & Error & Ellip. & Triang. & Error \\
\hline 201 & 31.5 & 10.58 & 0.98 & 1.44 & 31.78 & 39.03 & -0.19 & 7.82 & 6.88 & 0.14 \\
\hline 218 & 32.5 & 11.00 & 0.98 & 1.36 & 31.92 & 35.26 & -0.10 & 7.68 & 6.28 & 0.22 \\
\hline 217 & 34.5 & 10.93 & 0.99 & 1.72 & 36.80 & 39.30 & -0.06 & 9.75 & 6.61 & 0.47 \\
\hline 213 & 34.5 & 9.89 & 1.05 & 1.64 & 33.09 & 45.06 & -0.27 & 8.92 & 7.18 & 0.24 \\
\hline 206 & 35.0 & 8.74 & 1.34 & 1.76 & 33.88 & 35.46 & -0.04 & 10.79 & 7.83 & 0.38 \\
\hline 219 & 35.5 & 10.98 & 1.04 & 1.46 & 34.07 & 40.10 & -0.15 & 8.73 & 8.04 & 0.09 \\
\hline 204 & 35.5 & 12.44 & 1.18 & 1.66 & 43.85 & 52.57 & -0.17 & 12.76 & 10.16 & 0.26 \\
\hline 216 & 36.5 & 11.99 & 1.17 & 1.80 & 44.24 & 48.79 & -0.09 & 13.22 & 10.46 & 0.26 \\
\hline 215 & 37.0 & 10.71 & 1.03 & 1.54 & 34.18 & 40.89 & -0.16 & 8.90 & 8.27 & 0.08 \\
\hline 220 & 38.0 & 13.27 & 1.18 & 1.68 & 47.07 & 53.87 & -0.13 & 13.77 & 10.57 & 0.30 \\
\hline 209 & 38.5 & 11.31 & 1.28 & 1.74 & 42.48 & 48.37 & -0.12 & 13.19 & 10.12 & 0.30 \\
\hline 205 & 39.0 & 13.93 & 1.08 & 1.78 & 49.39 & 56.54 & -0.13 & 14.02 & 11.31 & 0.24 \\
\hline 214 & 39.0 & 12.71 & 1.30 & 1.64 & 46.38 & 54.21 & -0.14 & 14.19 & 9.82 & 0.44 \\
\hline 202 & 44.0 & 13.00 & 1.40 & 2.62 & 65.15 & 69.47 & -0.06 & 24.97 & 16.37 & 0.52 \\
\hline 207 & 44.5 & 16.39 & 1.54 & 2.12 & 74.43 & 89.35 & -0.17 & 28.02 & 19.76 & 0.42 \\
\hline
\end{tabular}
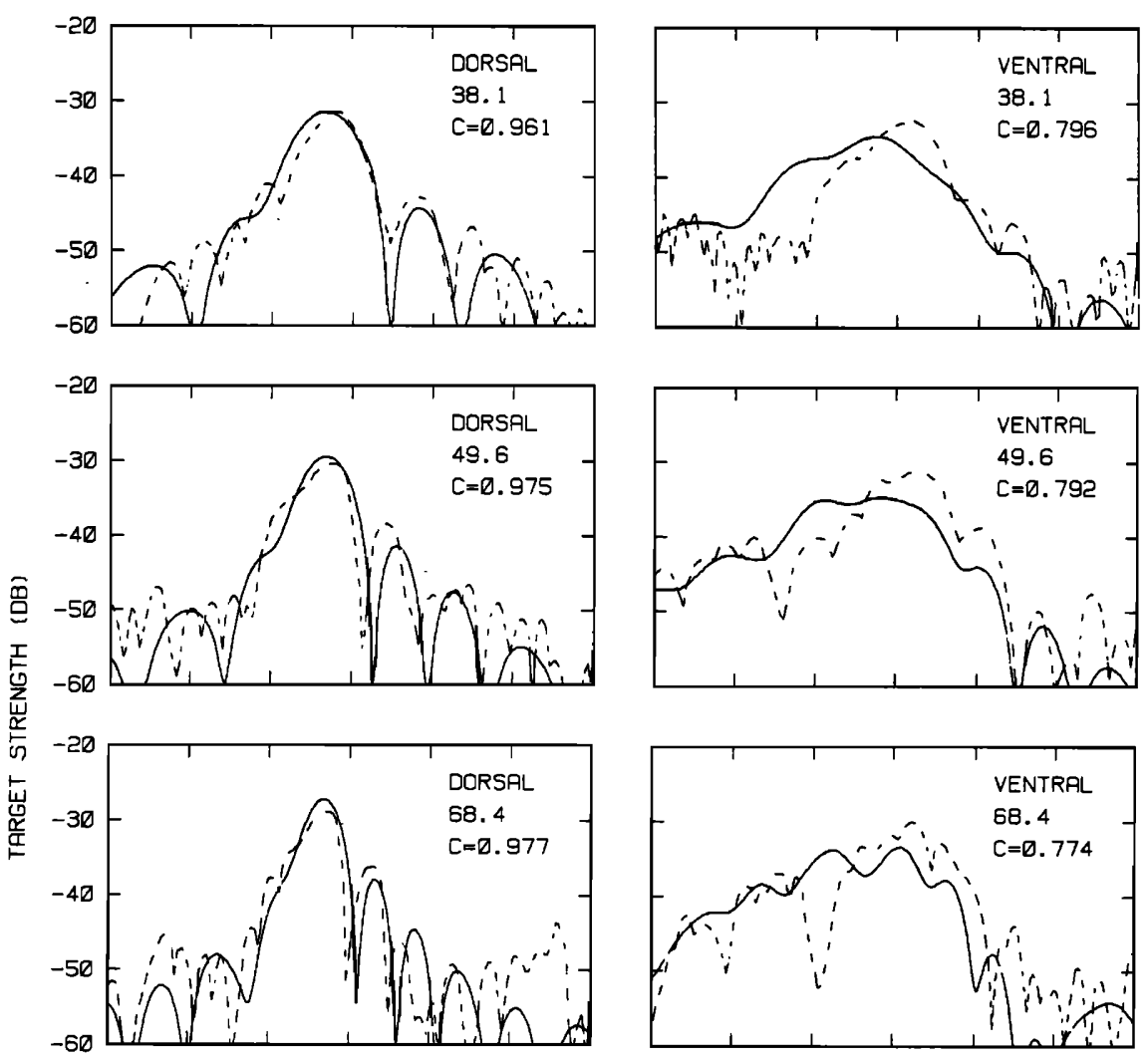

FIG. 3. Target strength functions of fish No. 201, a 31.5-cm pollack, distinguished by aspect and frequency in kilohertz. The correlation coefficient $C$ is given for corresponding computed and measured functions, drawn respectively

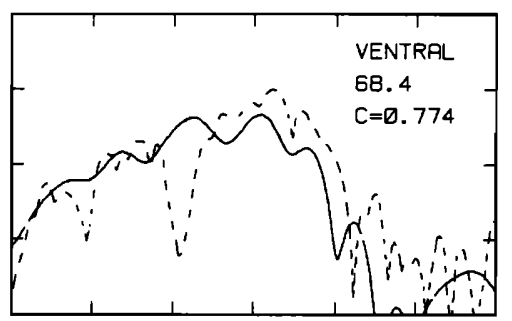
with solid and dashed lines.

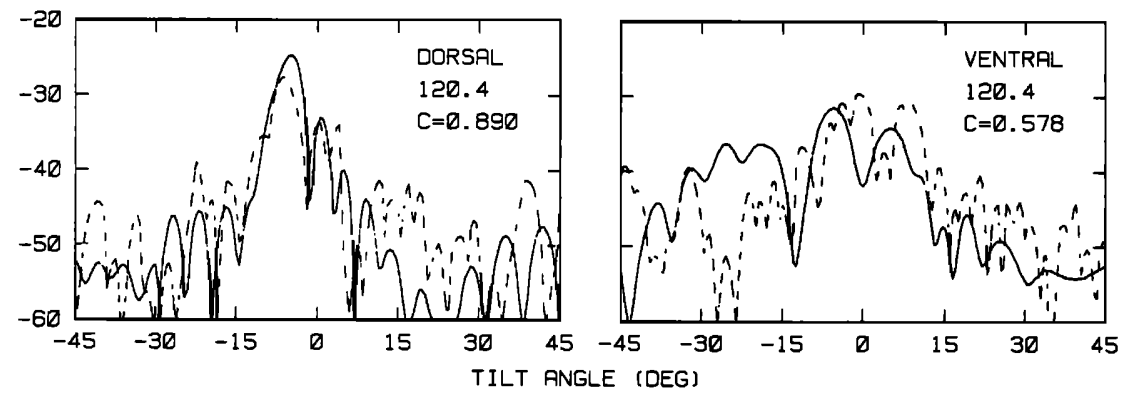



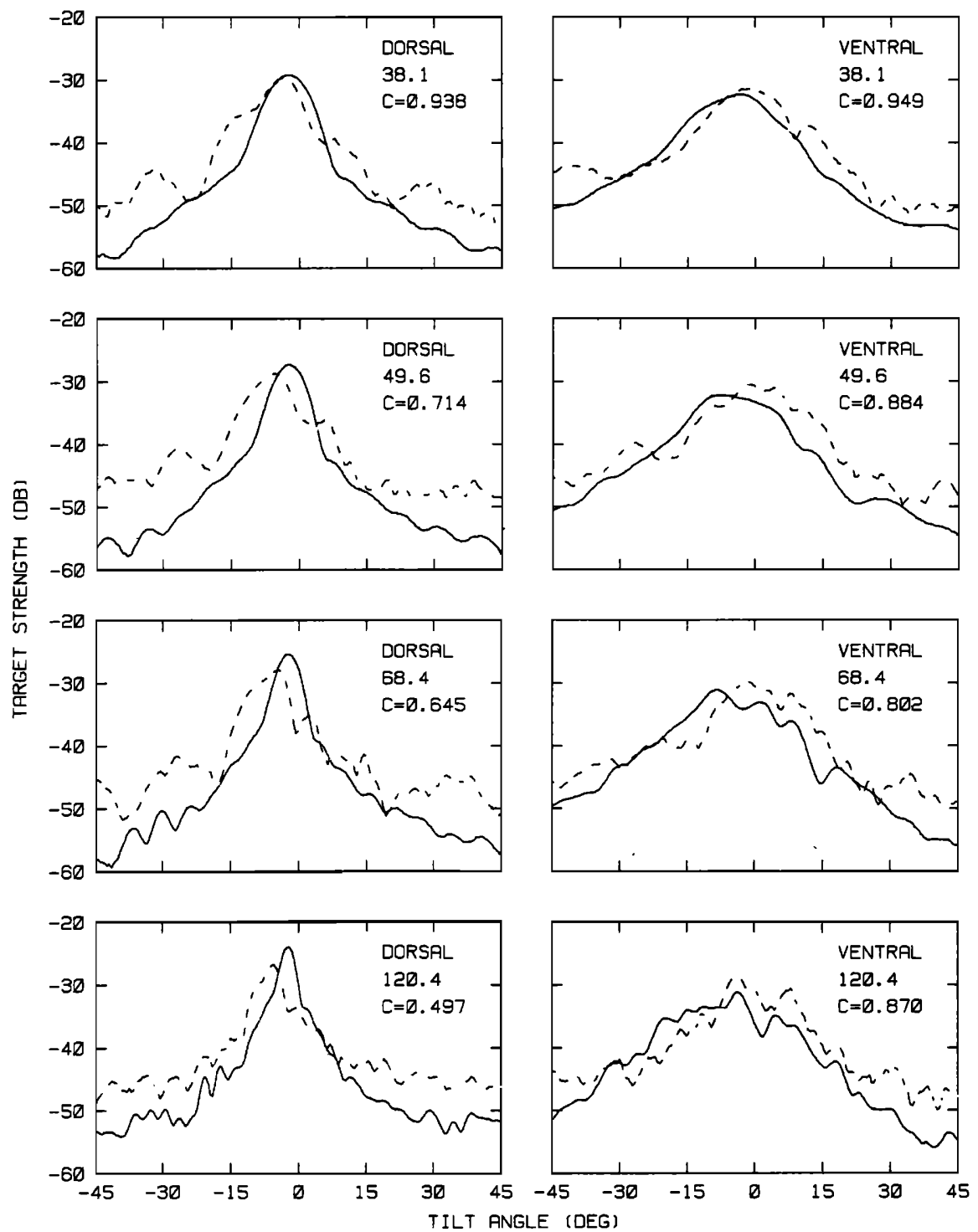

FIG. 4. Composite target strength functions of all 15 fish, presented in the pattern of Fig. 3. logarithmic conversion by Eq. (4).

In order to suggest the usefulness of swimbladder-based computations of target strength, two widely used expressions of target strength were investigated theoretically. These are the effective target strength and the probability density function (PDF) of target strength. Both of these measures depend on the distribution of fish orientation. To an excellent approximation in applications of vertical echo sounders, the orientation can be represented entirely by the tilt angle. ${ }^{39}$ This is illustrated by the display in Fig. 5 of the roll angle dependences of the dorsal aspect target strength functions of fish No. 201. The functions have been computed for roll angles from $-5^{\circ}$ to $+5^{\circ}$ in increments of $1^{\circ}$, and superimposed on corresponding figures, thus including the curves of Fig. 3, which represent the zero roll angle. The significant orientation is indeed the tilt angle.

The probability distribution of tilt angle is assumed to be normal in each of the several following computations. In particular, four different distributions are used. The first distribution is based on the only observational data on gadoids known to this author, namely, those due to Olsen. ${ }^{54}$ According to these, the distributon of tilt angle is normal, with a mean of $-4.4^{\circ}$ and a standard deviation of $16^{\circ}$. The other three distributions are assumed to have zero means and standard deviations of $0^{\circ}, 5^{\circ}$, and $10^{\circ}$, respectively. In addition to their theoretical value, the distributions may have practical value in representing other possible modes of behavior, for example, that of fast swimming at constant depth, for which the mean and standard deviation are plausibly expected to be very small, if not zero.

Consistent with the present aim of simplicity and level of approximation, the effect of perspective on the apparent tilt angle ${ }^{55}$ is included in the distribution function through the standard deviation. Assuming a circular half-beamwidth of $5^{\circ}$, as measured from the axis to the - 3-dB level, the effective standard deviations corresponding to those of $0^{\circ}, 5^{\circ}$, and $10^{\circ}$ are $2.5^{\circ}, 5.5^{\circ}$, and $10.2^{\circ}$, respectively. The effective standard deviation of Olsen's distribution is the same as its observation, namely, $16^{\circ}$.

The results of the averaging are presented in Table IV through the coefficient $b$ in the equation

$$
\overline{T S}=20 \log l+b,
$$



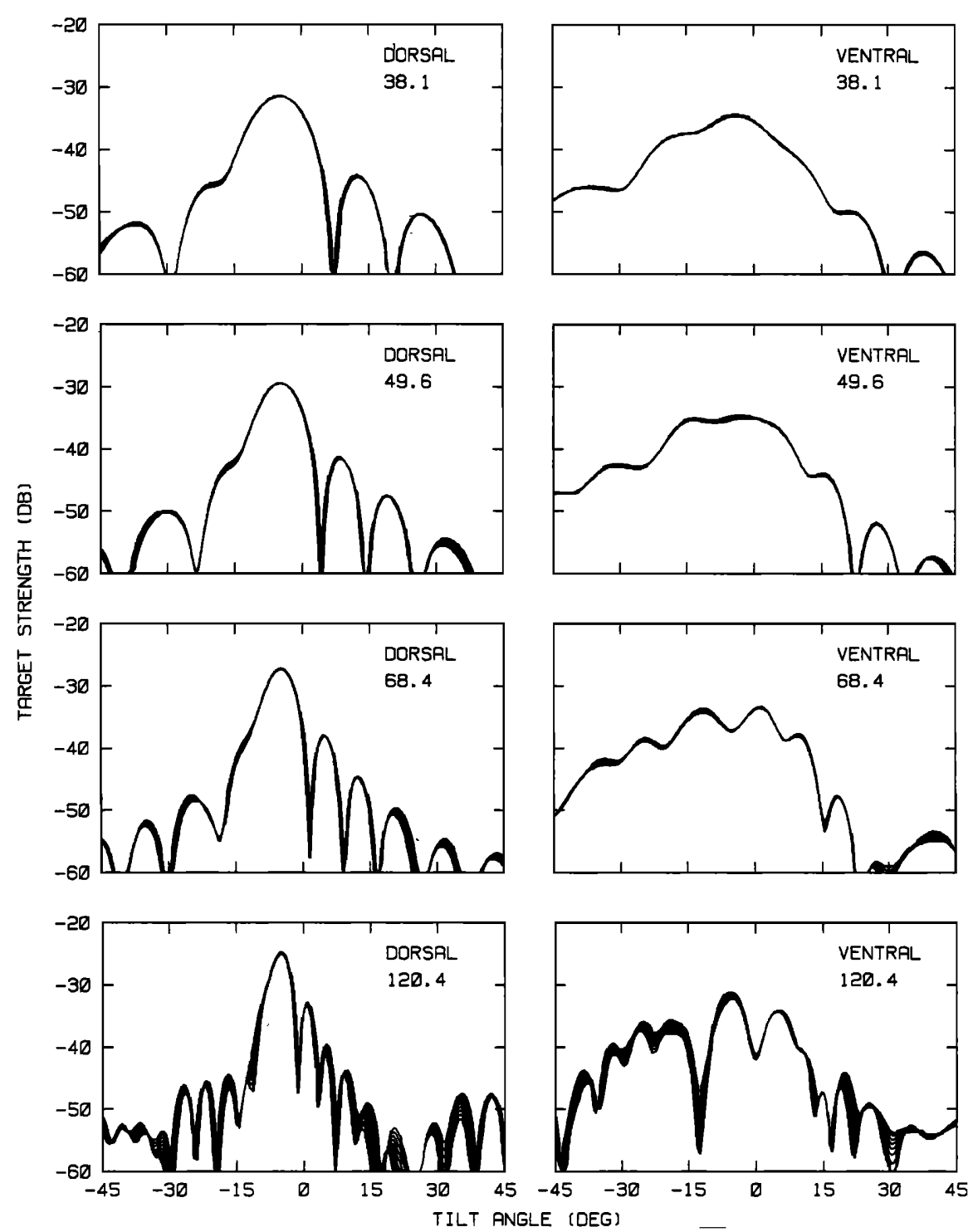

FIG. 5. Roll angle dependence of computed target strength functions of fish No. 201, derived by superimposing the respective functions computed separately for roll angles from $-5^{\circ}$ to $+5^{\circ}$ in increments of $1^{\circ}$. where $\overline{T S}$ is the effective target strength, and $l$ is the fish length in units of centimeters. The coefficient $b$ is determined by a least-mean-squares regression involving all 15 pairs of values of $\overline{T S}$ and $l$. The effective target strength of a single fish is determined by substituting the average backscattering cross section $A v(\sigma)$ for $\sigma$ in Eq. (4). Explicitly,

$$
A v(\sigma)=a^{-1} \int \sigma(\theta) g(\theta) d \theta
$$

where $g(\theta) / a$ is the PDF of tilt angle $\theta$, assumed normal until truncation at 3 s.d., and $a$ accomplishes the normalization,

$$
a=\int g(\theta) d \theta
$$

The effective integration limits in Eqs. (6) and (7) are $\bar{\theta}-3 s_{\theta}$ and $\bar{\theta}+3 s_{\theta}$, where $\bar{\theta}$ and $s_{\theta}$ denote the respective mean and standard deviation of the tilt angle distribution.

The PDF of target strength is shown in Fig. 6 for the group of 15 fish, assuming Olsen's tilt angle distribution $N(-4.4,16)$. Mathematically, the PDF of target strength is simulated through the prescription

$$
\begin{aligned}
f(\mathrm{TS}) \Delta \mathrm{TS}= & a^{-1} \int\left[\mathscr{H}\left(\mathrm{TS}^{\prime}-\mathrm{TS}\right)\right. \\
& \left.-\mathscr{H}\left(\mathrm{TS}^{\prime}-\mathrm{TS}-\Delta \mathrm{TS}\right)\right] g(\theta) d \theta,
\end{aligned}
$$

where the target strength value TS' is that of the subject target strength function for the particular $\theta$ in the integration, and $\mathscr{H}$ is the Heaviside step function, already defined in connection with Eq. (1). The integration is performed over the full range of $\theta$, hence from $\bar{\theta}-3 s_{\theta}$ to $\bar{\theta}+3 s_{\theta}$. In simulating the PDF for the group of fish, the PDF for each individual fish was first computed according to Eq. (8). The group PDF was then determined by simple arithmetic averaging of the individual PDFs.

To suggest the effect of behavior, the probability density function of the dorsal aspect target strength at $38 \mathrm{kHz}$ is shown in Fig. 7 for the other three tilt angle distributions: $N(0,0), N(0,5)$, and $N(0,10)$. The computations were per- 
TABLE IV. Regression coefficient $b$ in Eq. (5), together with the correlation coefficient $\rho$ and standard error SE, computed on the bases of the theoretically computed and measured target strength functions for each of four normal distributions of tilt angle.

\begin{tabular}{|c|c|c|c|c|c|c|c|c|c|}
\hline \multirow[b]{2}{*}{ Aspect } & \multirow{2}{*}{$\begin{array}{c}\text { Frequency } \\
(\mathbf{k H z})\end{array}$} & \multicolumn{2}{|c|}{ Tile angle (deg) } & \multicolumn{3}{|c|}{ Computed TS functions } & \multicolumn{3}{|c|}{ Measured TS functions } \\
\hline & & Mean & s.d. & $\rho$ & $b$ & SE & $\rho$ & $b$ & SE \\
\hline Dorsal & 38.1 & 0.0 & 0.0 & 0.956 & -62.2 & 1.3 & -0.055 & -63.5 & 1.3 \\
\hline Dorsal & 38.1 & 0.0 & 5.0 & 0.957 & -63.5 & 1.0 & 0.736 & -64.3 & 0.6 \\
\hline Dorsal & 38.1 & 0.0 & 10.0 & 0.950 & -65.3 & 0.8 & 0.892 & -65.7 & 0.4 \\
\hline Dorsal & 38.1 & -4.4 & 16.0 & 0.942 & -66.9 & 0.7 & 0.910 & -66.9 & 0.4 \\
\hline Dorsal & 49.6 & 0.0 & 0.0 & 0.947 & -60.9 & 1.3 & 0.409 & -64.8 & 1.1 \\
\hline Dorsal & 49.6 & 0.0 & 5.0 & 0.951 & -62.3 & 0.9 & 0.709 & -64.1 & 0.7 \\
\hline Dorsal & 49.6 & 0.0 & 10.0 & 0.941 & -64.3 & 0.7 & 0.826 & -65.0 & 0.6 \\
\hline Dorsal & 49.6 & -4.4 & 16.0 & 0.932 & -66.0 & 0.7 & 0.864 & -66.1 & 0.6 \\
\hline Dorsal & 68.4 & 0.0 & 0.0 & 0.913 & -59.8 & 1.4 & 0.160 & -64.7 & 1.2 \\
\hline Dorsal & 68.4 & 0.0 & 5.0 & 0.918 & -61.4 & 0.9 & 0.325 & -63.9 & 1.0 \\
\hline Dorsal & 68.4 & 0.0 & 10.0 & 0.899 & -63.4 & 0.7 & 0.686 & -64.8 & 0.7 \\
\hline Dorsal & 68.4 & -4.4 & 16.0 & 0.889 & -65.0 & 0.7 & 0.812 & -65.9 & 0.6 \\
\hline Dorsal & 120.4 & 0.0 & 0.0 & 0.696 & -59.6 & 1.8 & -0.296 & -64.8 & 1.6 \\
\hline Dorsal & 120.4 & 0.0 & 5.0 & 0.593 & -61.1 & 1.4 & -0.196 & -63.8 & 1.3 \\
\hline Dorsal & 120.4 & 0.0 & 10.0 & 0.524 & -63.1 & 1.3 & 0.246 & -64.7 & 1.1 \\
\hline Dorsal & 120.4 & -4.4 & 16.0 & 0.572 & -64.7 & 1.3 & 0.475 & -65.9 & 0.9 \\
\hline Ventral & 38.1 & 0.0 & 0.0 & 0.603 & -65.2 & 1.9 & 0.762 & -63.7 & 1.5 \\
\hline Ventral & 38.1 & 0.0 & 5.0 & 0.766 & -65.7 & 1.3 & 0.821 & -64.3 & 0.9 \\
\hline Ventral & 38.1 & 0.0 & 10.0 & 0.892 & -66.7 & 0.9 & 0.866 & -65.7 & 0.7 \\
\hline Ventral & 38.1 & -4.4 & 16.0 & 0.932 & -67.8 & 0.8 & 0.867 & -67.1 & 0.7 \\
\hline Ventral & 49.6 & 0.0 & 0.0 & 0.437 & -65.2 & 2.3 & 0.511 & -62.7 & 1.4 \\
\hline Ventral & 49.6 & 0.0 & 5.0 & 0.681 & -65.4 & 1.5 & 0.729 & -63.4 & 0.8 \\
\hline Ventral & 49.6 & 0.0 & 10.0 & 0.864 & -66.2 & 1.0 & 0.839 & -64.6 & 0.6 \\
\hline Ventral & 49.6 & -4.4 & 16.0 & 0.919 & -67.2 & 0.8 & 0.830 & -66.0 & 0.6 \\
\hline Ventral & 68.4 & 0.0 & 0.0 & 0.317 & -65.7 & 2.8 & 0.685 & -62.3 & 1.3 \\
\hline Ventral & 68.4 & 0.0 & 5.0 & 0.595 & -65.5 & 1.8 & 0.851 & -63.0 & 0.7 \\
\hline Ventral & 68.4 & 0.0 & 10.0 & 0.827 & -66.1 & 1.1 & 0.904 & -64.3 & 0.5 \\
\hline Ventral & 68.4 & -4.4 & 16.0 & 0.898 & -67.0 & 0.9 & 0.885 & -65.8 & 0.5 \\
\hline Ventral & 120.4 & 0.0 & 0.0 & 0.649 & -66.3 & 2.2 & 0.768 & -62.5 & 1.2 \\
\hline Ventral & 120.4 & 0.0 & 5.0 & 0.767 & -66.1 & 1.5 & 0.918 & -62.8 & 0.7 \\
\hline Ventral & 120.4 & 0.0 & 10.0 & 0.854 & -66.7 & 1.3 & 0.933 & -64.0 & 0.5 \\
\hline Ventral & 120.4 & -4.4 & 16.0 & 0.873 & -67.4 & 1.3 & 0.929 & -65.5 & 0.5 \\
\hline
\end{tabular}

formed both for fish No. 201, from Fig. 3, and for the group of 15 fish.

In those cases of averaging or PDF computation in which tilt angles less than $-45^{\circ}$ or greater than $45^{\circ}$ are assumed to occur with nonzero probability, the target strength is assumed to be equal to $-60 \mathrm{~dB}$. For the particular tilt angle PDFs used in the computations, only negligible error is incurred by this approximation.

\section{DISCUSSION}

\section{A. Particular results}

The introduced model aims to describe sound scattering by swimbladdered fish at rather high frequencies. The degree to which it succeeds is indicated by the agreement of computed and measured target strengths, especially the dorsal and ventral aspect functions, as in Figs. 3 and 4 . While the agreement is quite good in some cases, it is weaker in others, and in the particular cases of the composite functions, in Fig. 4 , systematic, frequency-independent differences are evident.
If the agreement between theory and experiment were uniformly $100 \%$, then this discussion would be at an end, since the validity of the measured functions in applications to swimming fish has already been established. ${ }^{48}$ Inasmuch as the agreement is imperfect, and theoretical computation remains a desideratum, it is necessary to examine other measures of target strength.

The selected, derived measures of target strength are those of greatest usefulness in acoustic studies of fish abundance, namely, the average and the probability density function or PDF. The average target strength is determined from the average of the backscattering cross sections of all 15 fish specimens, and expressed in terms of the regression coefficient $b$ in Eq. (5). Comparison of the corresponding coefficients for each aspect, frequency, and behavior mode, as expressed through the parameters of the tilt angle distribution, reveals these marked differences: averages of dorsal aspect target strengths computed on the basis of the theoretical functions uniformly exceed those of the measured functions, except in a single case of equality, while the reverse is true for the ventral aspect target strengths. However, the averages 

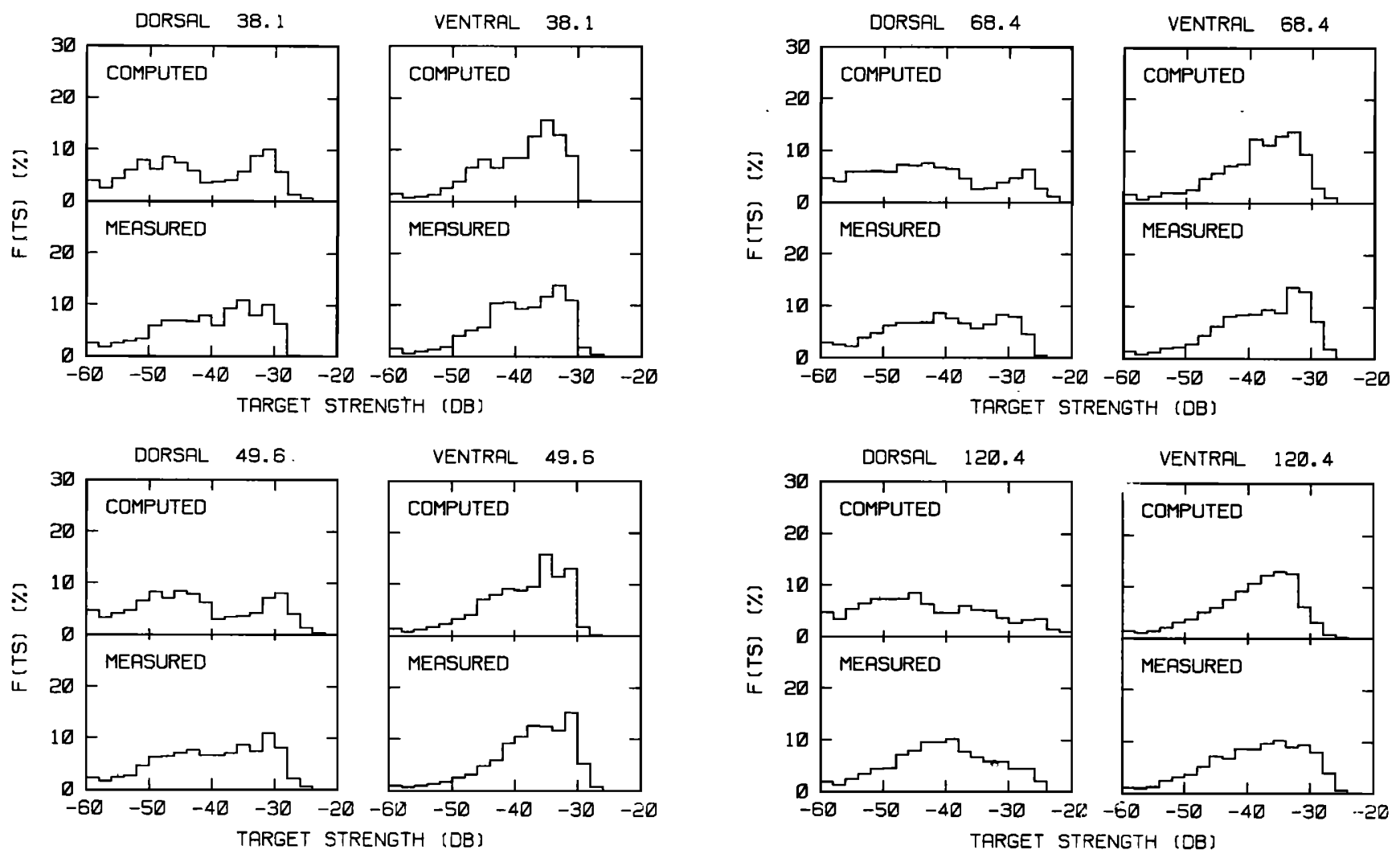

FIG. 6. Simulated probability density functions of target strength for the group of 15 fish, assuming Olsen's tilt angle distribution $N(-4.4,16)$. The designations "computed" and "measured" refer to the source of the underlying target strength functions.

are consistent, or differ by not more than the sum of the respective standard errors, in seven of the eight cases for the only naturally observed gadoid tilt angle distribution, $\mathrm{Ol}$ sen's $N(-4.4,16) .{ }^{54}$ The averages are also consistent in six of the eight cases for the distribution $N(0,10)$. The offending cases are confined to the ventral aspect target strengths at frequencies above $38 \mathrm{kHz}$. This is to be expected from the character of the systematic differences in Fig. 4. The general
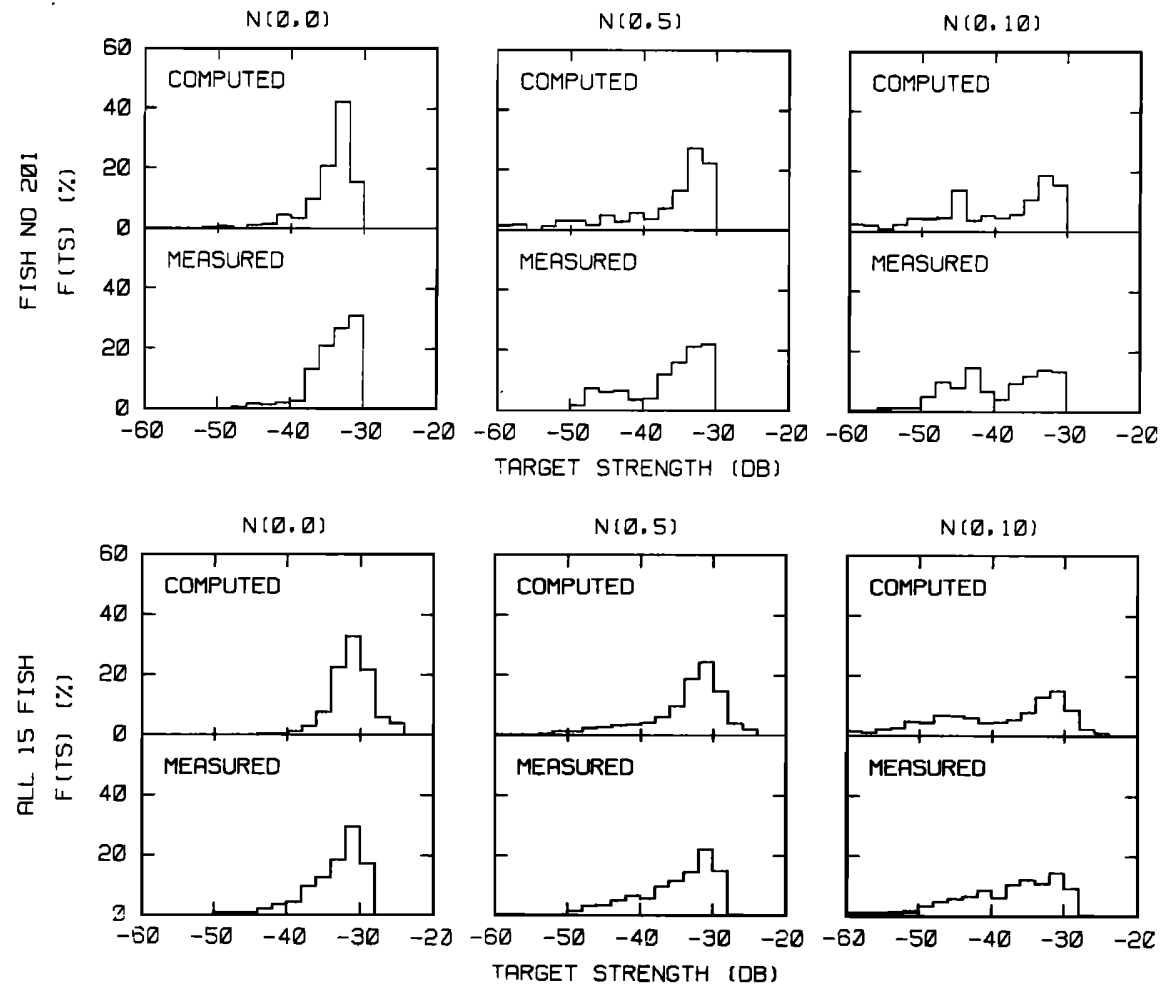

FIG. 7. Simulated probability density functions of dorsal aspect target strengths at $38 \mathrm{kHz}$ for both fish No. 201 and the group of 15 fish, assuming the tilt angle distributions $N(0,0)$ $N(0,5)$, and $N(0,10)$. 
inconsistency of dorsal aspect averages for the postulated fast-swimming mode of behavior, $N(0,0)$, except at $38 \mathrm{kHz}$, where the averages are similar, is also understandable in terms of a systematic difference in Fig. 4. This is that of the less-negative positions of the theoretical peaks compared with the corresponding measured peaks.

Thus the averages reveal systematic differences arising from those of the basic functions in Fig. 4. Nonetheless, for the presumed most important case, that of a gadoid in its natural spawning habitat, the averages based on theoretical computation are consistent with those based on measurement.

The averages, as expressed through the regression coefficient, are also consistent with Nakken and Olsen's gadoid target strength data at $38 \mathrm{kHz}^{39,40}$ This agreement obtains for each of the four behavior modes, both for the entire data set, composed of dorsal aspect target strength functions for 171 specimens of cod (Gadus morhua), saithe, and pollack of lengths from 6.7 to $96 \mathrm{~cm}$, and for that data subset composed of the functions for the $\mathbf{4 2}$ specimens with lengths between 31.5 and $44.5 \mathrm{~cm}$, i.e., the present length range. In the case of the other frequency used by Nakken and Olsen in their measurements, that of $120 \mathrm{kHz}$, the data are uniformly lower for corresponding behavior modes. Differences in calibration are believed responsible for the discrepancy.

Corresponding PDFs of target strength, in Figs. 6 and 7, are quite similar, although not in perfect agreement. Given the noted differences in averages, the PDFs themselves must differ. What differences are present within pairs of experimentally and theoretically based PDFs do not seem to be systematically related to frequency, aspect, or behavior mode. Undoubtedly this reflects partly not only the limited sample size, but also the general insignificance of such differences.

Individual PDFs of a given type do exhibit systematic differences with or dependences on the several parameters. Because of the basic similarity of corresponding experimentally and theoretically based PDFs, the pattern observed for one type also applies for the other. Three systematic dependences are enumerated. (1) The PDFs generally become more diffuse with increasing frequency. This is due to the increasingly erratic or variable nature of the underlying target strength functions, as illustrated for a single fish in Fig. 3. The frequency dependence is weak, however, because of the basic lobe-type structure of finite-body scattering. (2) Ventral aspect PDFs are generally more concentrated, or less diffuse, than corresponding dorsal aspect functions. The formal reason is observed in the exemplary Fig. 3: backscattering in the ventral aspect is generally less directional than in the dorsal aspect. This is a direct consequence of differences in curvature of the swimbladder, the belly side being more rounded than the dorsal side. (3) Variations in PDFs with behavior can be quantified through the standard deviation in tilt angle distribution. As this increases, the PDF becomes more diffuse. This is distinctly observed in the sets of PDFs in Fig. 7, for which the mean tilt angle is identically $0^{\circ}$. The same pattern is upheld by the pertinent PDFs of Fig. 6, namely, those applicable at $38 \mathrm{kHz}$ in dorsal aspect, although the mean tilt angle of these is $-4.4^{\circ}$.
All in all, comparisons based on theory and experiment show important agreements, particularly with respect to current uses of downward-looking echo sounders operating at $38 \mathrm{kHz}$. Systematic differences that are present in the dorsal aspect results at $38 \mathrm{kHz}$ are generally innocuous, probably owing to reasons of anatomy and basic acoustics. Nonetheless, the causes of these and other larger discrepancies are sought, both to illuminate the nature of the model and to better define its limitations.

\section{B. Critique of model}

Clearly, in an acoustic sense, a swimbladdered fish is more than just a bubble with an ideal pressure-release surface. Both bone and flesh have been positively implicated as important scattering elements at quite high frequencies, ${ }^{20}$ as have fish scales at still higher frequencies. ${ }^{56}$ The gas content of the swimbladder is very significant at quite low frequencies,where the phenomenon of resonance is well known. ${ }^{11,14,17,19,57-61}$ However, at the intermediate frequencies of the present study, with fish lengths spanning the range from 8 to 36 acoustic wavelengths, there is good reason to believe that a swimbladdered fish is, in an acoustic sense, little more than an ideal pressure-release surface. The studies of McCartney and Stubbs ${ }^{11}$ and Edwards and Armstrong ${ }^{26,27}$ especially, in addition to that of Ref. 25, have shown, by process of elimination, that the swimbladder is the preeminent scattering organ of fish. This is true for both physoclists and physostomes, i.e., fish whose swimbladders respectively lack and possess an external duct. A mean contribution of from $90 \%$ to $95 \%$ to the echo energy is expected.

Thus the general agreement of theory and experiment in the results can be understood, and therefore the source of the systematic differences must be sought elsewhere than in the physical model. In particular, the mathematical model and its realization must be examined.

The Kirchhoff approximation is a well-known fiction. ${ }^{41,62,63}$ It has had notable successes in both acoustics and optics, for scalar and vector waves, and is generally worth trying at an early stage in modeling scatterers. Clearly, too, diffraction is always present in finite-body scattering. According to Tables I and III, the product of acoustic wavenumber and maximum transverse dimension is of the order of 2 to 13, while that for the longitudinal dimension varies from 14 to 83. Thus, in the present case, significant or nonnegligible diffraction effects might be expected with respect to the transverse dimension of the swimbladder. ${ }^{64}$

Techniques for rigorously including diffraction effects exist, but have not yet been applied to actual swimbladder shapes. At present, the most closely related computation with diffraction has been the $T$-matrix solution to rather low-frequency scattering by a soft prolate ellipsoid. ${ }^{23}$

Possible errors due to the use of the monochromatic expression, Eq. (3), instead of the general wideband formula, Eq. (2), have already been observed to be negligible. The reason is simply that the pulse lengths are very much greater than the acoustic wavelength, the ratios varying from 24 to 82 for the parameters in Table I. The receiver frequency response functions used in the wideband computations were 
those of Ref. 46, with displacement of the function for the 38$\mathrm{kHz}$ system by the mere $0.1 \mathrm{kHz}$ necessary to align the center frequencies.

Errors in scattering predictions may also arise from the particular method of swimbladder triangulation. This is but one of many diverse, if not divergent, techniques for triangulating three-dimensional surfaces. How to do it best, i.e., optimally, for the kinds of convoluted and involuted surfaces typical of the swimbladders of commercially important fish eludes this author, although better methods, requiring more modeling or computing resources than expended here, are recognized.

It is always possible that the swimbladder form changes in the course of the shock-freezing process, although this is believed unlikely or negligible by Ona. ${ }^{52}$ Evidence for change is, however, present in the systematic differences in angular locations and strengths of main peaks in the composite target strength functions in Fig. 4. There, the noted, frequency independent differences can be correlated with hypothesized deformations in the dorsal and ventral swimbladder surfaces. For example, if the dorsal surface were to lose some of its natural swayback, as due to a too powerful stretching in maintaining the elongate posture during the freezing operation, then it would act as a more directional scatterer. The dorsal surface would be flatter; hence more of its area could contribute coherently to the echo in the normal direction, and the main scattering lobe or peak would become sharper, i.e., narrower. In like manner, it can be argued that the ventral surface would be crimped by the applied tension, as in a flexure, thereby diminishing the effective scattering area. The decrease in normal incidence backscattering and increase in main lobe width follows immediately. Of course, such speculation should also be considered in the larger context of the comparative target strength measurements and execution of the triangulation procedure.

Systematic errors may arise in the measurements through the method of tethering and suspension, although these are believed to be very small, perhaps $1^{\circ}$ or $2^{\circ}$ at most. Systematic errors may also arise in the triangulation process if the horizontal or other alignment reference is incorrectly identified. Again, the error is believed to be small, about $1^{\circ}$ or $2^{\circ}$.

For completeness, and also in defense of the basic model, it is noted that the triangulation process, in its maiden trial, was not problem-free. Because of the use of different or poorly distinguished visual alignment references in a number of photographed swimbladder cross sections, the goodness of the underlying contour data cannot be asserted unequivocally. Resulting errors could be the cause of discrepancies, especially at large tilt angles, where the backscattering strength is generally weaker, hence more subject to small, otherwise extraneous, deformities in swimbladder form. Of course, discrepancies at large angles may also be due to other fish parts. Fish bone and flesh may indeed contribute significantly to the echo where the swimbladder contribution is inherently weak.

Whatever the net effect of triangulation errors is, however, it might be obscured by another measurement-related error source: the presence of noise in the measurements, which may have been further corrupted by undetected, small rolling or twisting movements of the fish under tilting. Neither of these causes of target strength variation is treated in the model, although not precluded by it either.

Another experimental source of error may depend on the target strength measurement of the surface-adapted fish being performed at $2.5-\mathrm{m}$ depth, followed by biological measurement and shock-freezing at atmospheric pressure. An attempt was made to investigate this effect theoretically by scaling the swimbladder in accordance with free-bubble compression or expansion between surface and a $2.5-\mathrm{m}$ depth, notwithstanding known differential effects on swimbladder elasticity. ${ }^{36,65}$ However, no significant improvement was obtained by repeating the described model computations with swimbladder dimensions scaled linearly by the factor $1.25^{1 / 3}$, whether down or up in size.

\section{Future work}

A chronic need in the acoustic assessment of fish abundance is for knowledge about the target strength of fish. The new model can supply this whenever swimbladder data are available. Systematic morphometric studies of the swimbladders of commercially important species over the length ranges of interest in surveying operations are, therefore, highly desirable.

Because of the still-unknown effect of depth on target strength, ${ }^{59,66,67}$ additional studies must be directed to describing the effect of pressure changes on the form of the swimbladder. Of course, the complexities of swimbladder regulation must be appreciated. Thus the habits or patterns of swimbladder filling and emptying by physoclists and physostomes under vertical migration must be learned. Two important sources of data on pressure effects are in situ target strength measurements of fish under vertical migration and radiography of fish in pressure chambers. Neither is expected to be sufficient in itself, but together may solve, through a modeling exercise, an important and outstanding problem in fisheries acoustics.

The model itself should be investigated further. One object would be to define the contribution of diffraction effects, especially at lower frequencies. A consequence of such an investigation could be a demonstrated extension of the model to lower frequencies, albeit above resonance.

A second object in investigating the model would be to specify the element size in surface triangulation needed to achieve a given accuracy in target strength computation. The basic acoustics, to wit, diffraction theory, gives some guidance. In order to resolve a given physical feature by scattering, the wavelength should not exceed the characteristic dimension, at least not by very much. Conversely, for a fixed frequency, only features with characteristic dimensions exceeding the wavelength can be sensed. A measurement scale size, or resolution cell, of the order of $\frac{1}{16}$ to $\frac{1}{8}$ of the acoustic wavelength is probably adequate for representing the swimbladder form, but the precise connection with the intended accuracy in target strength computation should be determined. With control over the accuracy, exercise of the model can be simplified. The possibility of using standard 
forms, although generally not simple geometric shapes, to represent the swimbladder surface may then become apparent. Such forms may be especially useful in theoretical investigations of the effect of depth on target strength.

\section{CONCLUSIONS}

The important acoustic properties of swimbladdered fish of lengths at least from 8 to 36 acoustic wavelengths can be determined from a swimbladder morphometry, without reference to other measurements. In particular, the structure and absolute magnitude of dorsal and ventral aspect target strength functions can be determined by solution of the wave equation for a soft, swimbladder shape in the Kirchhoff approximation, without diffraction.

For gadoids of lengths from 31.5 to $44.5 \mathrm{~cm}$, and frequencies from 38 to $120 \mathrm{kHz}$, average dorsal aspect target strengths can be computed for any reasonable behavior pattern. Use of individually averaged target strengths $\overline{\mathbf{T S}}$ and fish lengths $l$ in the regression equation $\overline{\mathrm{TS}}=20 \log l+b$ enables the coefficient $b$ to be determined to within present experimental limits. For the kind of behavior observed by Olsen, this implies the value $-66.9 \mathrm{~dB}$, for $l$ expressed in centimeters, for surveying with a downwards-looking, 38$\mathrm{kHz}$ echo sounder with a $5^{\circ}$ half-beamwidth. Neither swimming nor ordinary rolling movements is expected to affect this result or, indeed, other averaging computations based solely on the tilt angle dependence of the target strength function.

Use of theoretically derived data to simulate probability density functions of target strength gives results indistinguishable from those based on conventional constrained-single-fish measurements.

\section{ACKNOWLEDGMENTS}

L. Midttun and O. Nakken are thanked for innumerable discussions throughout the course of the work. E. Ona is thanked for his varied assistance, especially in biological matters. Professor R. T. Beyer and Professor C. Elbaum are thanked for their hospitality during the author's visit at the Department of Physics, Brown University, 1982-83. The financial support of the Norwegian Council for Fisheries Research during the project at Skogsvajen, in summer 1980, is gratefully acknowledged.

'L. Midttun, "Fish and other organisms as acoustic targets," Rapp. P.-v. Réun. Cons. Int. Explor. Mer 184, 25-33 (1984).

${ }^{2}$ D. H. Cushing, "Some echo-sounding experiments on fish," J. Cons. Int. Explor. Mer 20, 266-275 (1955).

${ }^{3}$ D. H. Cushing and I. D. Richardson, "Echo sounding experiments on fish," Fish. Invest., Ser. 2 18(4), 1-34 (1955).

${ }^{4}$ F. R. Harden Jones and G. Pearce, “Acoustic reflexion experiments with perch (Perca fluviatilis Linn.) to determine the proportion of the echo returned by the swimbladder," J. Exp. Biol. 35, 437-450 (1958).

${ }^{5}$ R. J. H. Beverton and R. W. Blacker, "Experiments on quantitative echo sounding in deep water,"Fish. Invest., Ser. 2 22(9), $22-48$ (1959).

${ }^{6}$ D. H. Cushing, F. R. Harden Jones, R. B. Mitson, G. H. Ellis, and G. Pearce, "Measurements of the target strength of fish," J. Br. Inst. Radio Eng. 25, 299-303 (1963).

${ }^{7}$ R. W. G. Haslett, "The acoustic back-scattering cross sections of short cylinders," Br. J. Appl. Phys. 15, 1085-1094 (1964).
${ }^{8}$ R. W. G. Haslett, "Acoustic backscattering from an air-filled cylindrical hole embedded in a sound-translucent cylinder," Br. J. Appl. Phys. 17, 549-561 (1966).

${ }^{9} \mathrm{~K}$. Shibata, "Study on details of ultrasonic reflection from individual fish," Bull. Fac. Fish. Nagasaki University (29) (1970).

${ }^{10} \mathrm{~K}$. Shibata, "Experimental measurement of target strength of fish," in Modern Fishing Gear of the World, edited by H. Kristjonsson (Fishing News, London, 1971), Vol. 3, pp. 104-108.

"B. S. McCartney and A. R. Stubbs, "Measurements of the acoustic target strengths of fish in dorsal aspect, including swimbladder resonance," $\mathrm{J}$. Sound Vib. 15, 397-420 (1971).

${ }^{12}$ R. W. G. Haslett, "Determination of the acoustic back-scattering patterns and cross sections of fish," Br. J. Appl. Phys. 13, 349-357 (1962).

${ }^{13} \mathrm{~L}$. Midttun and I. Hoff, "Measurements of the reflection of sound by fish," Fiskeridir. Skr. Ser. Havunders. 13(3), 1-18 (1962).

${ }^{14} \mathrm{I}$. B. Andreeva, "Scattering of sound by air bladders of fish in deep soundscattering ocean layers," Sov. Phys.-Acoust. 10, 17-20 (1964).

${ }^{15}$ R. W. G. Haslett, "Physics applied to echo sounding for fish," Ultrasonics 2, 11-22 (1964).

${ }^{16}$ R. W. G. Haslett, "Acoustic backscattering cross sections of fish at three frequencies and their representation on a universal graph," Br. J. Appl. Phys. 16, 1143-1150 (1965).

${ }^{17} \mathrm{D}$. E. Weston, "Sound propagation in the presence of bladder fish," in Underwater Acoustics, edited by V. M. Albers (Plenum, New York, 1967), Vol. 2, Chap. 5, pp. 55-88.

${ }^{18}$ I. L. Kalikhman, "Scattering of sound by fish and fish models," Proc. AllUnion Res. Inst. Mar. Fish. Oceanog. (VNIRO) 135, 83-88 (1978), in Russian.

${ }^{19}$ R. H. Love, "Resonant acoustic scattering by swimbladder-bearing fish," J. Acoust. Soc. Am. 64, 571-580 (1978).

${ }^{20}$ R. W. G. Haslett, "The fine structure of sonar echoes from underwater targets, such as fish," in Ultrasonics International 79 Conf. Proc., Graz, Austria, 15-17 May 1979 (IPC, Guildford, England, 1979), pp. 307-320.

${ }^{21} \mathrm{~K}$. Huang and C. S. Clay, "Backscattering cross sections of live fish: PDF and aspect," J. Acoust. Soc. Am. 67, 795-802 (1980).

${ }^{22}$ K. I. Yudanov and I. L. Kalikhman, "Sound scattering by marine animals," in Proc. Meeting on Hydroacoustical Methods for the Estimation of Marine Fish Populations, Cambridge, MA, 25-29 June 1979, edited by J. B. Suomala, Jr. (Draper, Cambridge, MA, 1981), Vol. 2, pp. 53-95.

${ }^{23} \mathrm{G}$. Cooper and J. A. G. Temple, "Calculations of acoustic scattering from ellipsoidal voids: bends, krill and fish," Ultrasonics 21, 171-176 (1983).

${ }^{24} \mathrm{C}$. S. Clay and B. G. Heist, "Acoustic scattering by fish-Acoustic models and a two-parameter fit," J. Acoust. Soc. Am. 75, 1077-1083 (1984).

${ }^{25} \mathbf{K}$. G. Foote, "Importance of the swimbladder in acoustic scattering by fish: A comparison of gadoid and mackerel target strengths," J. Acoust. Soc. Am. 67, 2084-2089 (1980).

${ }^{26} \mathrm{~J}$. I. Edwards and F. Armstrong, "Measurement of the target strength of live herring and mackerel," FAO Fish. Rep. (300), 69-77 (1983).

${ }^{27} \mathrm{~J}$. I. Edwards and F. Armstrong, "Target strength measurements on herring, sprat and mackerel," Coun. Meet. Int. Coun. Explor. Sea 1983/B:23, Copenhagen, Denmark.

${ }^{28}$ G. R. Bell and J. E. Bateman, "Some radiographic observations on the gastrointestinal and urinary systems of anesthetized Pacific salmon $\left(O_{n}\right.$ corhynchus)," Can. J. Zool. 38, 199-202 (1960).

${ }^{29}$ E. J. Denton, "The buoyancy of fish and cephalopods," Prog. Biophys. 11, 178-234 (1961).

${ }^{30}$ R. W. G. Haslett, "Measurements of the dimensions of fish to facilitate calculations of echo-strength in acoustic fish detection," J. Cons. Int. Explor. Mer 27, 261-269 (1962).

${ }^{31} \mathrm{G}$. Fahlén, "Morphological aspects on the hydrostatic function of the gas bladder of Clupea harengus L.," Acta Univ. Lund. II 1967(1), 1-49.

${ }^{32}$ R. K. C. Chang and J. J. Magnuson, "A radiographic method for determining gas bladder volume," Copeia 1968(1), 187-189.

${ }^{33} \mathrm{~J}$. B. Steen, "The swimbladder as a hydrostatic organ," in Fish Physiology, edited by W. S. Hoar and D. J. Randall (Academic, New York, 1970), Vol. 4, pp. 413-443.

${ }^{34}$ O. Sand and A. D. Hawkins, "Acoustic properties of the cod swimbladder," J. Exp. Biol. 58, 797-820 (1973).

${ }^{35}$ J. T. Yelverton, D. R. Richmond, W. Hicks, K. Saunders, and E. R. Fletcher, "The relationship between fish size and their response to underwater blast," Defense Nuclear Agency, Washington, DC, Rep. DNA 3677T (1975).

${ }^{36} \mathbf{P}$. Tytler and J. H. S. Blaxter, "The effect of swimbladder deflation on pressure sensitivity in the saithe Pollachius virens," J. Mar. Biol. Assoc. U.K. 57, 1057-1064 (1977). 
${ }^{37}$ J. H. S. Blaxter, "The swimbladder and hearing," in Hearing and Sound Communication in Fishes, edited by W. N. Tavolga, A. N. Popper, and R. R. Fay (Springer, New York, 1981), Chap. 3, pp. 61-70.

${ }^{38}$ A. D. Hawkins and A. A. Myrberg, Jr., "Hearing and sound communication under water," in Bioacoustics: A Comparative Approach, edited by B. Lewis (Academic, New York, 1983), Chap. 13, pp. 347-405.

${ }^{39} \mathrm{O}$. Nakken and K. Olsen, "Target strength measurements of fish," Rapp. P.-v. Réun. Cons. Int. Explor. Mer 170, 52-69 (1977).

${ }^{40} \mathrm{~K}$. G. Foote and O. Nakken, "Dorsal aspect target strength functions of six fishes at two ultrasonic frequencies," Fisken og Havet, Ser. B, 1978(3), 1-95.

${ }^{41}$ M. Born and E. Wolf, Principles of Optics (Pergamon, London, 1959).

${ }^{42}$ N. F. Haines and D. B. Langston, "The reflection of ultrasonic pulses from surfaces," J. Acoust. Soc. Am. 67, 1443-1454 (1980).

${ }^{43}$ National Defense Research Committee, Physics of Sound in the Sea (Department of the Navy, Washington, DC, 1969), originally issued as Summary Technical Report of Division 6, Vol. 8 (Columbia U. P., Washington, DC, 1946).

${ }^{44} W$. G. Neubauer, " $A$ summation formula for use in determining the reflection from irregular bodies," J. Acoust. Soc. Am. 35, 279-285 (1963).

${ }^{45} \mathrm{D}$. M. Johnson, "Model for predicting the reflection of ultrasonic pulses from a body of known shape," J. Acoust. Soc. Am. 59, 1319-1323 (1976).

${ }^{46} \mathrm{~K}$. G. Foote, "Optimizing copper spheres for precision calibration of hydroacoustic equipment," J. Acoust. Soc. Am. 71, 742-747 (1982).

${ }^{47}$ R. J. Urick, Principles of Underwater Sound (McGraw-Hill, New York, 1975), 2nd edition.

${ }^{48}$ K. G. Foote, "Linearity of fisheries acoustics, with addition theorems," J. Acoust. Soc. Am. 73, 1932-1940 (1983).

${ }^{49} I$. Røttingen, "On the relation between echo intensity and fish density," Fiskeridir, Skr. Ser. Havunders. 16, 301-314 (1976).

${ }^{50} \mathrm{~J}$. Dalen, A. Raknes, and I. Rфttingen, "Target strength measurements and acoustic biomass estimation of capelin and 0-group fish," Coun. Meet. Int. Coun. Explor. Sea 1976/B:37, Copenhagen, Denmark.

${ }^{51} \mathrm{M}$. Aksland, "Acoustic abundance estimation of the spawning component of the local herring stock in Lindaaspollene, western Norway," Fiskeridir. Skr. Ser. Havunders. 17, 297-334 (1983).

${ }^{52}$ E. Ona, "Mapping the swimbladder's form and form-stability for theoretical calculations of acoustic reflection from fish," thesis, University of Ber- gen (1982), in Norwegian.

${ }^{53}$ E. Ona, "Tilt angle measurements on herring," Coun. Meet. Int. Coun. Explor. Sea 1984/B:19, Copenhagen, Denmark.

${ }^{54} \mathrm{~K}$. Olsen, "Orientation measurements of cod in Lofoten obtained from underwater photography and their relation to target strength," Coun. Meet. Int. Coun. Explor. Sea 1971/B:17, Copenhagen, Denmark.

${ }^{55}$ K. G. Foote, “Averaging of fish target strength functions," J. Acoust. Soc. Am. 67, 504-515 (1980).

${ }^{56} \mathrm{~K}$. J. Diercks and T. G. Goldsberry, "Target strength of a single fish," J. Acoust. Soc. Am. 48, 415-416 (1970).

${ }^{57}$ D. V. Holliday, "Resonance structure in echoes from schooled pelagic fish," J. Acoust. Soc. Am. 51, 1322-1332 (1972)

${ }^{58} \mathrm{G}$. Sundnes and $\mathrm{O}$. Sand, "Studies of a physostome swimbladder by resonance frequency analyses," J. Cons. Int. Explor. Mer 36, 176-182 (1975).

${ }^{59}$ A. D. Hawkins, "Fish sizing by means of swimbladder resonance," Rapp. P.-v. Réun. Cons. Int. Explor. Mer 170, 122-129 (1977).

${ }^{60} \mathrm{D}$. V. Holliday, "The use of swimbladder resonance in the sizing of schooled pelagic fish," Rapp. P.-v. Réun. Cons. Int. Explor. Mer 170, 130-135 (1977)

${ }^{61}$ A. Lovik and J. Hovem, "An experimental investigation of swimbladder resonance in fishes," J. Acoust. Soc. Am. 66, 850-854 (1979).

${ }^{62}$ J. D. Jackson, Classical Electrodynamics (Wiley, New York, 1962).

${ }^{63}$ R. New and T. J. Eisler, "On high-frequency scattering methods: The need for error bounds and domains of validity," J. Acoust. Soc. Am. 53, 373-374 (1973).

${ }^{64}$ W. C. Meecham, "On the use of the Kirchhoff approximation for the solution of reflection problems," J. Rat. Mech. Anal. 5, 323-334 (1956).

${ }^{65}$ J. H. S. Blaxter, E. J. Denton, and J. A. B. Gray, "The herring swimbladder as a gas reservoir for the acoustico-lateralis system," J. Mar. Biol. Assoc. U.K. 59, 1-10 (1979).

${ }^{66} \mathrm{~K}$. Olsen, "Some experiments on the effect on target strength of fish undertaking vertical migrations,"' Coun. Meet. Int. Coun. Explor. Sea 1976/ B:42, Copenhagen, Denmark.

${ }^{67}$ F. R. Harden Jones and P. Scholes, "The swimbladder, vertical movements, and the target strength of fish," in Proc. Meeting on Hydroacoustical Methods for the Estimation of Marine Fish Populations, Cambridge, MA, 25-29 June 1979, edited by J. B. Suomala, Jr. (Draper, Cambridge, MA, 1981), Vol. 2, pp. 157-181. 